\title{
EL LUCRATIVO “NEGOCIO” DEL PROTECTORADO ESPAÑOL
}

\section{Corruption under the Spanish Protectorate}

\author{
María Rosa de Madariaga Álvarez-Prida
}

Investigadora independiente. Exfuncionaria de la UNESCO

ma.rosamadariaga@gmail.com

Cómo citar este artículo/Citation:

María Rosa de MADARIAGA ÁlVAREZ-PRIDA, "El lucrativo "negocio" del protectorado español", Hispania Nova, 16, págs. 590-619, DOI: https://doi.org/10.20318/hn.2018.4049
Copyright: (c) HISPANIA NOVA es una revista debidamente registrada, con ISSN 1138-7319 y Depósito Legal M 9472-1998. Los textos publicados en esta revista están -si no se indica lo contrario- bajo una licencia Reconocimiento-Sin obras derivadas 3.0 España de Creative Commons. Puede copiarlos, distribuirlos y comunicarlos públicamente siempre que cite su autor y la revista y la institución que los publica y no haga con ellos obras derivadas. La licencia completa se puede consultar en: http://creativecommons.org/licenses/by-nd/3.0/es/deed.es
Resumen: En mi artículo me propongo examinar la situación en materia de corrupción y las diferentes corruptelas existentes en la Zona del Protectorado español en Marruecos. Algunas de estas corruptelas, como el soborno de los jefes tribales rifeños, para conseguir su adhesión, y el contrabando de armas, eran ya habituales antes de la firma del tratado de Protectorado en 1912. Otras, como las estafas, los desfalcos y el estraperlo llegarían a ser más tarde prácticas comunes. Este proceso se hizo más evidente en los años de la guerra civil bajo el mandato del alto comisario franquista, Juan Beigbeder, hasta generalizarse y convertirse la corrupción en sistémica, sobre todo durante el mandato de los altos comisarios Varela y García Valiño en los años cuarenta y cincuenta del pasado siglo.

Palabras clave: Sobornos, estafas, desfalcos, estraperlo, Varela, Valiño.
Abstract: The object of this paper is to examine the largescale corruption and the varied smaller-scale corrupt practices that flourished in the Spanish Protectorate Zone of Morocco. Some of these, such as the bribing of tribal chiefs of the Rif region to secure their support and gunrunning were already common before the signing of the Protectorate treaty in 1912. Others, such as fraud, embezzlement, and smuggling were to become common practice later on. This process became more evident during the Spanish Civil War years under the Francoist High Commissioner, Juan Beigbeder, but was to become rife during the forties and fifties especially under High Commissioners Varela and García Valiño.

Keywords: Briberies, frauds, embezzlements, smuggling, Varela, Valiño. 
A propósito del Protectorado de España en Marruecos, dije en una ocasión que "aquel tinglado" había costado "miles de vidas humanas y millones de pesetas, solo para beneficio de unos pocos, que hicieron allí su agosto y se enriquecieron gracias a negocios sucios como el estraperlo, los desfalcos y otras corruptelas"1. Estas palabras resumen bien la cruda realidad de lo que representaron los cuarenta y cuatro años de Protectorado español en Marruecos. En las páginas que siguen trataremos de exponer los principales ámbitos en los que todas estas lacras encontraron terreno abonado.

\section{La "compra de voluntades" y el tráfico de armas}

Incluso antes de la firma del tratado del Protectorado en 1912, eran ya moneda corriente ciertas prácticas corruptas. De una de ellas, la "compra de voluntades" se hablaba con naturalidad en los documentos oficiales, como medio necesario para no verter sangre y ocupar pacíficamente el territorio; la otra, de distinta naturaleza, pero al fin y al cabo también corrupción, el "tráfico de armas", se ocultaba pudorosamente, sobre todo teniendo en cuenta que muchos de los que se dedicaban a este "negocio" eran militares, que hacían "Patria" vendiendo armas a los que se suponía debían combatir.

La "compra de voluntades" o soborno era habitualmente practicada por las autoridades españolas de las plazas fuertes ocupadas por España en el Norte de África para con los jefes y notables de las cabilas aledañas. Esta práctica había sido instaurada desde hacía tiempo, pues tenemos noticias de que ya era habitual en Orán, ocupado por España en 1509 y evacuado en 1792, donde los llamados "moros de paz" colaboraban con el ocupante, proporcionándoles información sobre el territorio y

\footnotetext{
1 María Rosa de MADARIAGA, Marruecos, ese gran desconocido. Breve historia del Protectorado español, p. 20, Madrid, Alianza Editorial, 2013.
} 
facilitando los intercambios con el hinterland ${ }^{2}$. Esta especie de espías o confidentes que recibían una retribución a cambio de sus servicios llegarían con el tiempo a constituir redes de "moros amigos" o "moros adictos" quienes, al estar remunerados por España, eran designados también con el nombre de "moros pensionados". Cuando en las cabilas se contaba con varios "moros amigos" o "moros adictos" se formaba entonces lo que se conocía como "partido español", cuya misión consistía, entre otras cosas, en: informar a las autoridades españolas sobre el estado de ánimo de los cabileños y crear entre ellos un clima favorable al avance de las tropas españolas, así como formar "harkas amigas", es decir, grupos irregulares de hombres armados que, bajo el mando del caíd de la cabila, a sueldo de España, auxiliaban a las tropas españolas en la ocupación de nuevos territorios.

Además de la "compra de voluntades", en su "política de atracción" de jefes o notables, las autoridades españolas recurrían también a otros métodos de corrupción como los de otorgar puestos en la administración local de las plazas ocupadas por España o becas a los hijos de los "moros amigos", para que prosiguieran sus estudios en la Península. A la firma del Protectorado en 1912, eran cientos los jefes y notables de distintos niveles que percibían un sueldo de España. En documentos de la Oficina Central de Asuntos Indígenas de Melilla hay extensas relaciones de "moros adictos", con expresión del sueldo y gratificaciones que recibían, según el prestigio del personaje y los servicios prestados ${ }^{3}$.

A finales de 1912 la Capitanía General de Melilla pasó a ser Comandancia General, y al frente de ella fue nombrado el general Francisco Gómez Jordana, que defendía su "gestión militar" y su "acción política" como el mejor medio de conseguir avances sin efusión de sangre ${ }^{4}$. Fue con Gómez Jordana con quien la práctica de la "compra de voluntades" adquirió carta de naturaleza y se institucionalizó de manera

\footnotetext{
${ }^{2}$ Diego SUÁREZ MONTAÑÉS, Historia del Maestre último que fue de Montesa y de su hermano Felipe de Borja. La manera cómo gobernaron las memorables plazas de Orán y Mazalquivir... siendo allí Capitanes Generales (Texto impreso), Madrid, Sociedad de Bibliófilos Españoles, 1889, Sobre el papel de los "moros de paz", véanse particularmente las páginas 66-67.

${ }^{3}$ Archivo General Militar de Madrid (de ahora en adelante, AGMM), Comandancia General de Melilla, Documentos de Abdelkrim, legajo 1, carpeta, 1, rollo 738.

${ }^{4}$ De Annual a la República. Comisión de Responsabilidades. Documentos relacionados con la información instruida por la llamada "Comisión de Responsabilidades" acerca del desastre de Annual, p. 34, Madrid, Javier Morata Editor, 1931.
} 
oficial. Nombrado alto comisario de España en Marruecos en 1915, sus métodos de "atracción política" se extendieron por todo el territorio y se aplicaron sistemáticamente en los avances de las tropas que, ante la opinión pública y coreados por la prensa triunfalista, aparecían como heroicas hazañas de los jefes y oficiales españoles. Así se ganaban cruces y condecoraciones, cuando, en realidad, la mayoría de las veces, los avances se hacían a base de distribuir billetes del Banco de España y sacos de cebada, como denunciaba el diputado socialista Indalecio Prieto, en su famoso discurso en el Congreso el 21 de noviembre de 1922:

"Se avanzó por el territorio de Beni Saíd, presentándose ante la opinión española como una conquista de las armas y como fruto de la concepción de un genio guerrero, solamente escudados en el hambre de aquellos indígenas que, perdidas las cosechas, sin elementos de manutención, consentían nuestro avance, toleraban el emplazamiento de la posiciones, eran los guías de nuestras columnas a cambio, a los jefes, de unos fajos de billetes de Banco, a cambio, los más modestos, de unos sacos de cebada con que hicieran unas tortas para no morir de hambre" .

No eran estos métodos evidentemente los más apropiados para cumplir la tan cacareada "misión civilizadora" de los países occidentales. Sin que el modelo colonizador francés fuese ni mucho menos digno de alabanza, pues, llegado el caso, podía ser tan zafio y corrupto como el español, es muy cierto que había mayor preocupación por atraerse a la población construyendo hospitales y escuelas y tratando de elevar su nivel cultural y sus condiciones de vida.

Del otro método, al que nos hemos referido, muy extendido también desde tiempo inmemorial, el del "tráfico de armas" tenemos numerosos testimonios, ya desde antes del establecimiento del Protectorado. En periodos de guerra, este lucrativo negocio experimentaba, como era de esperar, un importante auge, aunque en el caso de Marruecos, con cabilas hostiles a la ocupación de su territorio y siempre dispuestas a conseguir armas por cualquier medio, sobre todo de contrabando, era normal que ésta fuera una actividad permanente.

\footnotetext{
${ }^{5}$ Indalecio PRIETO, Discursos parlamentarios sobre la guerra de Marruecos, discurso del 21 de noviembre de 1922 sobre las "Responsabilidades del derrumbamiento de la Comandancia de Melilla", p. 94, Málaga, Editorial Algazara, 2003.
} 
Durante la guerra de Melilla de 1893, se destapó un escándalo del que la prensa se hizo eco, aunque sin sacar todo a relucir. Se trataba de un tráfico de armas, la mayoría de origen español, en el que estaban implicados numerosos españoles. Era evidente que este tráfico no podía realizarse sin la complicidad de funcionarios civiles y militares, cuya obligación consistía precisamente en impedirlo. La red de traficantes se extendía por Algeciras, Málaga, Cádiz y Melilla, donde se citaban los nombres de los que se dedicaban a este comercio, al que no podían ser ajenas las fábricas que expedían los productos de su industria. Era difícil pensar que miles de armas podían salir de las fábricas, viajar en ferrocarriles y embarcar en los puertos para ser alijadas en África, sin que nadie admitiese haber visto nada ${ }^{6}$. De la búsqueda de depósitos de armas en Melilla se encargó a la Guardia Civil. En una casa del barrio del Polígono se encontraron más de doscientos fusiles, pistolas, tercerolas y miles de cartuchos. Fueron detenidos como autores del contrabando con los rifeños dos españoles. En otra casa del mismo barrio, esta vez propiedad de un judío que tenía una tienda de ropa, se encontraron varias cajas de fusiles Remington, pistolas, municiones y piezas de recambio, cuyo dueño era un español, que fue detenido y juzgado con arreglo al código militar $^{7}$. Era evidente que este tráfico contaba con múltiples complicidades, incluidas algunas al más alto nivel. Después de que el general García Margallo hiciera una salida de Melilla dispuesto a que lo mataran los rifeños, se decía que había recibido una carta de Madrid, cuyo contenido se relacionaba con su muerte, calificada por algunos de suicidio, circulaban rumores de que había preferido morir al enterarse de que iba a ser relevado de su puesto y sancionado por negligencia o complicidad en la venta clandestina de armas españolas a los rifeños ${ }^{8}$.

Años más tarde, durante la guerra de Melilla de 1909, el contrabando de armas seguía siendo particularmente activo. Los alijos de armas procedentes de Hamburgo

\footnotetext{
${ }^{6}$ Diario de Barcelona, 18 de noviembre de 1893.

7 Rafael GUERRERO, Crónica de la guerra (1893), pp. 190 y 247, Barcelona, Establecimiento Tipográfico Editorial de Timoteo Susany, s/a. Véase también, Diario de Barcelona, del 13 de noviembre de 1893.

${ }^{8}$ Stanley G. PAYNE, Los militares y la política en la España contemporánea, pp. 56-57, París, Ruedo Ibérico, 1968. Respecto de esta explicación sobre la muerte de Margallo, que figura con un asterisco a pie de página, Payne aclara que tenía su origen en las abundantes pruebas del extraordinario grado de corrupción en el ejército de Marruecos y de venta de armas a los rifeños, pero que estaba "enteramente desprovista de fundamento".
} 
eran transportados por buques alemanes y desembarcados entre el Peñón de Vélez de la Gomera y el de Alhucemas. Se decía que había incluso rifeños que se habían trasladado a Hamburgo con tal fin $^{9}$. El contrabando de Gibraltar con Alhucemas era también activo ${ }^{10}$. Había asimismo un intenso contrabando desde Argelia, según informaba en sus despachos el cónsul de España en Orán ${ }^{11}$. Al contrabando de dedicaría también el súbdito español vecino de Tetuán, Isaac Pinto, de cuyas actividades se informaba ya en comunicación reservada del 12 de octubre de 1902. Los que se dedicaban a este tráfico elegían puntos seguros de la costa y lejanos del Peñón de Vélez, desde el que podían ser vistos. Las armas procedían de Gibraltar y Tetuán por mar, y del Kiss por tierra. El referido Isaac Pinto ya habría engañado al ministro de España en Tánger, haciendo un importante contrabando de géneros de comercio por Alhucemas, al conseguir que aquél le recomendase con una carta al gobernador de dicha plaza, en la que le pedía que complaciese a Pinto en una transacción de cebada y otros granos que deseaba importar en el Rif. Pinto había hecho creer al ministro de España en Tánger que era un valioso "auxiliar de España, y que con el pretexto de comercio libre iba a descubrir "manejos de un agente extranjero entre los Bocoya" ${ }^{12}$. Se sospechaba que Isaac Pinto proseguía actividades de venta de armas de contrabando a los rifeños. Según confidencias, segadores procedentes de Argelia y desembarcados en Tánger, salían de Tetuán rumbo al Rif en cárabos y todo tipo de embarcaciones, y algunos faluchos, que desde Tánger, Gibraltar y Tetuán se dirigían al Rif con cargamento de sal, llevaban en realidad armas ocultas bajo esa carga. De otro lado, el comandante militar de Alhucemas comunicaba al gobernador militar de Melilla que el pesquero Lynx empezaba a dedicarse al contrabando de

\footnotetext{
${ }^{9}$ Telegrama del gobernador militar de Ceuta al Gobernador militar de Melilla, recogiendo informaciones del ministro de España en Tánger, del 27 de julio de 1909, AGMM, Comandancia General de Melilla, año 1909, legajo 36, carpeta 7, rollo 183.

${ }^{10}$ En telegrama del 27 de julio de 1909, el ministro de la guerra informaba al gobernador militar de Melilla que el armador del vapor Cabo Páez era sospechoso del contrabando de armas entre Gibraltar y Alhucemas, AGMM, Ibidem.

${ }^{11}$ Telegrama del 7 de septiembre de 1909, AGMM, Ibidem.

${ }^{12}$ Comunicación del gobernador militar del Peñón de Vélez sobre las actividades de contrabando de armas de Isaac Pinto, del 11 de junio de 1904, AGMM, Ibidem.
} 
armas, siendo el maquinista Juan Carpintero, quien se entendía con "moros" en Málaga $^{13}$.

Por la correspondencia mantenida entre el gobernador militar de Melilla y el cónsul de España en Orán, el encargado de la Legación de España en Tánger y otras autoridades se ve que las actividades de contrabando de armas, ya bastante extendidas en las costas rifeñas, se habían intensificado tras la agitación provocada en las cabilas por la reanudación de las obras del ferrocarril minero en 1909. Según noticias de origen marroquí, transmitidas por conducto de la Legación de España en Tánger, por el instructor jefe español de la policía jerifiana de Tetuán, los puntos por donde se hacía contrabando de armas y municiones en la costa de Marruecos estaban situados en Gomara, en Bocoya y en Beni Urriaguel.

Destacaba entre los que hacían este contrabando, el llamado Civera (o Sibera), de la cabila de Bocoya, "muy conocido en las plazas españolas", que era el que hacía contrabando a mayor escala. Civera, que estaba en relaciones con un tal "Enrique de Gibraltar", quien era el que facilitaba los fondos, utilizaba todo tipo de estratagemas para burlar la vigilancia de las autoridades encargadas de reprimir el contrabando de armas. De él se decía que solía venir a la Península "disfrazado", es decir, vestido de europeo, que era rubio, y que hablaba perfectamente español ${ }^{14}$. Se le consideraba un "individuo peligroso". Solía ir a Barcelona y a otros puntos de la Península "para adquirir armas y municiones" ${ }^{15}$, aunque no era solo dentro de España por donde Civera se movía, sino que también se trasladaba a países europeos, en los que mantenía contactos con una serie de proveedores.

Por proximidad y por ser estrechos los intercambios con el Norte de Marruecos, el contrabando con Gibraltar era importante. Se sospechaba que el laúd José Luis, con matrícula de Gibraltar, transportaba no armas, pero sí plomo con el que los cabileños fabricaban municiones ${ }^{16}$. Los vapores que se dedicaban al tráfico ilegal iban a tomar la

\footnotetext{
${ }^{13}$ Despacho del 16 de junio de 1909, AGMM, Ibidem.

14 Telegrama del ministro de Estado al comandante en jefe del Ejército de Operaciones de Melilla (general Marina), del 9 de octubre de 1909, Ibidem.

15 Telegrama del ministro de España en Tánger, Merry del Val, al ministro de Estado, del 8 de octubre de 1909, AGMM, Ibidem.

${ }^{16}$ Telegrama del comandante militar de Alhucemas, del 3 de marzo de 1909, AGMM, Ibidem.
} 
mercancía a las aguas de Larache, de buques alemanes que se los entregaban en alta mar, y ellos las transportarían después para desembarcarlas en los alrededores de Ceuta, sin llegar a Melilla. Se señalaba que los buques sobre los que debería extremarse la vigilancia eran el vapor español Cabo Páez, con matrícula de Palamós, y cuyo armador habría hecho fortuna vendiendo armas y municiones al Rif; el vapor Quetzal, con matrícula de San Sebastián, cuyo armador Miguel Díaz, residía en Tetuán; el vapor James Haynes, que hacía la misma carrera que los anteriores, y cuyos armadores eran los hermanos Coriot, hebreos naturalizados españoles; y el vapor Lady Love, que se había abanderado provisionalmente en el consulado español bajo el nombre de Jaime Pinto, el cual, por lo que le habían asegurado, se iba a dedicar al contrabando de armas, dado que su armador Isaac Pinto había estado

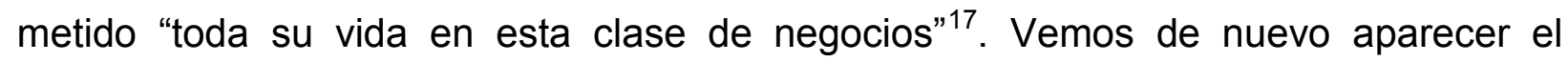
nombre de Isaac Pinto, en apariencia respetable hombre de negocios, que llegaría a ser socio nada menos que del duque de Tovar, hermano del conde de Romanones, y bajo capa traficante de armas ${ }^{18}$. No sería el único armador "respetable" en hacer su fortuna por esos medios. Por regla general, todos los vapores que hacían la carrera a las costas del norte de África solían llevar "algo de contrabando de guerra", pues, aunque los armadores no lo autorizasen, los capitanes lo hacían por su cuenta y riesgo. Las armas y municiones las tomaban en alta mar, y la mayoría procedían de Hamburgo ${ }^{19}$.

Todo este activo contrabando que allí se desarrollaba no habría podido existir si los traficantes no contaran con ciertas complicidades. Queda por saber hasta dónde y a qué nivel éstas llegaban.

\footnotetext{
17 Comunicación del cónsul de España en Gibraltar al gobernador militar de Melilla, de fecha 23 de julio de 1909, AGMM, Ibidem.

${ }^{18}$ Israelitas, naturalizados españoles, los hermanos Isaac y Abraham Pinto eran socios del duque de Tovar y de los hermanos Mannesmann. Después de la Primera Guerra Mundial y la eliminación de los intereses alemanes en Marruecos, los Mannesmann encontrarían la fórmula para mantener allí su presencia por medio de los Pinto y del duque de Tovar. Sobre los hermanos Pinto, véase María Rosa de MADARIAGA, España y el Rif. Crónica de una historia casi olvidada, pp. 259-260, Melilla, Ciudad Autónoma de Melilla.UNED- Centro Asociado de Melilla, 2008 (3ª edición).

${ }^{19}$ Comunicación del cónsul de España en Gibraltar al gobernador militar de Melilla, de fecha 23 de julio de 1909, AGMM, Comandancia General de Melilla, 1909, legajo n 36, carpeta nº 7, rollo 183.
} 
Al contrabando de armas con el Rif se refería también la prensa extranjera, particularmente la francesa, lo que motivó las protestas oficiales del gobierno español contra Le Matin y L'Écho de Paris. En un artículo del 31 de julio de 1909 de su corresponsal especial en Orán, este último periódico decía que no podía uno menos de sonreírse al leer los telegramas que llegaban de Melilla de fuente española, anunciando las medidas adoptadas para la vigilancia del contrabando de guerra, cuando todo el mundo sabía en Orán que uno de los principales tráficos en Melilla era el de las armas. El corresponsal seguía diciendo que él mismo había tenido a la vista un contrato de un gobierno extranjero para el suministro de armas a los rifeños, y fotografías en las que se veía el desarrollo de las operaciones de contrabando en Mar Chica. En una de ellas, se podía reconocer a un "comandante español de artillería, hombre de confianza del gobernador militar, ocupado en vigilar el desembarco de cajas de fusiles". "Todo el mundo sabe aquí"- proseguía el citado corresponsal- "que un general, muerto desde entonces, percibía 8 francos por arma entregada a los marroquíes. Los recibos firmados por ese general han circulado aquí por varias manos". En este mismo artículo se decía que en Melilla era del dominio público que las mujeres de los oficiales españoles pagaban con cartuchos a los cabileños sus compras de gallinas, y que el día de la fiesta de Melilla se habían distribuido como premio a los marroquíes fusiles máuser.

\section{Malversación de fondos y desfalcos}

Después de la firma del tratado de Protectorado en 1912, Marruecos se convirtió aún más para muchos no solo en un medio de hacer carrera rápida, sino también de llevar una vida a todo tren o de aumentar su peculio. Las corruptelas y latrocinios que allí se daban, aunque ya se barruntaban por los rumores cada vez más insistentes que circulaban por Marruecos y en la Península, saldrían plenamente a relucir después del desastre de Annual, en julio de 1921, en los debates en el Congreso y en la prensa. El diputado del Partido Reformista, Solano, pronunció el 21 de octubre de 1921 un violento discurso, en el que denunció en el ejército expedicionario la corrupción, la malversación de fondos y las lacras del juego y la prostitución. El diputado denunció que las razones de que todos los rifeños tuvieran un máuser, idéntico al de las tropas 
españolas, se debía fundamentalmente a que había oficiales, que, para mantener su lujo, sus vicios y sus queridas en Melilla o en Tetuán, habían hecho contrabando de armas y habían sido expulsados sin ruido de sus regimientos. Solano amenazó incluso con dar el nombre de un general que había sido condecorado y del que se decía que había ganado cuatro millones de pesetas con el contrabando de armas. En lo tocante a los oficiales de la Policía Indígena, Solano los acusó de robar, asesinar y cometer todo tipo de tropelías en las cabilas. Había en Melilla, aseguró, individuos que cobraban seiscientas pesetas de sueldo, pero gastaban al mes una 12.000 o 14.000 pesetas con mujeres, mientras que los soldados indígenas e encontraban en un estado lamentable, porque los capitanes se embolsaban las raciones. Se refirió al caso de un capitán que había asesinado a un notable marroquí para robarle una alfombra que había costado 25.000 pesetas $^{20}$.

Después del desastre de Annual salieron a relucir muchos testimonios sobre los abusos de los oficiales de la Policía Indígena, que se extralimitaban en su autoridad de manera escandalosa, hasta el punto de llegar a tomar artículos de los comercios sin pagarlos e imponer también a los cabileños multas excesivas con carácter arbitrario.

Son asimismo numerosos los testimonios de escándalos de malversación de fondos para saldar deudas de juego, jugar grandes cantidades y llevar un gran tren de vida. Había que sacar el dinero de donde fuera, si no se era de familia rica. Los que no lo eran, la mayoría, lo obtenían directamente de las compañías, escuadrones o baterías. Además de los casinos, había "salas de juego privadas", como la instalada por varios oficiales en una de las tiendas del campamento de Sidi Aisa, consistente en una ruleta que había llevado el teniente de Regulares, Ricardo Burguete, hijo del general del mismo nombre. Uno de los jugadores, que había perdido su dinero, metió mano a la consignación de la compañía, de la que tuvo que sacar el adelanto de su paga del mes, hasta apropiarse de todo el dinero de la consignación. Hubo una inspección, en la que se descubrieron los desfalcos de dos capitanes, que no habían tenido tiempo de reponer el dinero que habían sacado de la caja, y a los que se

${ }^{20}$ De esta feroz denuncia del diputado Solano, de la corrupción en el Protectorado, informaba extensamente el Bulletin du Comité de l'Afrique Française, noviembre de 1921, pp. 360-361 
expulsó del ejército ${ }^{21}$. Los desfalcos en las unidades eran frecuentes, lo que suponía que se pagase con retraso a los soldados indígenas o que incluso no se les pagase.

El caso de desfalco que hizo correr más tinta en aquellos años fue quizá el del llamado "millón de Larache", al que el periodista de El Sol, Rafael Lopez Renda, dedicó un libro. Aunque era Melilla la ciudad que se llevaba la palma como "lupanar y ladronera"22, en palabras de Indalecio Prieto en su famoso discurso en el Congreso el 21 de octubre de 1921, en este caso el suceso no tuvo lugar en la ciudad española, cabeza de la Comandancia Militar de la región oriental, sino en la región occidental del Protectorado, más concretamente en Larache, donde a finales de 1922 un capitán de Intendencia, Jordán, destacado en dicha ciudad, fue detenido por el desfalco de un millón y medio de pesetas procedentes de los "beneficios" obtenidos por sus compañeros y que debían todos repartirse. La triquiñuela consistía en que los parques del arma de Intendencia entregaban a los cuerpos de tropas, a cambio de vales, mercancías compradas por gestión directa, contrariamente a las prescripciones reglamentarias, conforme a las cuales las compras debían hacerse por concurso. Las compras se prestaban a todo tipo de artimañas con los proveedores, a quienes se pedía recibos en blanco o a precios superiores. Teniendo en cuenta que los cuerpos de tropas estaban mal dotados y carecían con frecuencia de créditos para cubrir necesidades suntuarias y particulares, se prestaban con frecuencia a arreglos ilícitos con Intendencia, de los que unos y otros sacaban beneficios, también ilícitos. De acuerdo con los jefes de Cuerpo, Intendencia entregaba cantidades inferiores a las indicadas en los vales, y, para los suministros no expedidos, remitía dinero. Las sumas enviadas por este procedimiento no correspondían en general a más de la mitad de las mercancías "economizadas", de manera que el cuerpo de tropa y la Intendencia obtenían, por medio de este ardid, un beneficio más o menos igual. Las economías se realizaban sobre todo con la avena y la paja destinadas a los caballos y mulos, la leña para cocinar la comida de los soldados y la gasolina. Con estas trampas, el parque militar de Larache obtenía regularmente 300.000 pesetas de ahorros, que se repartían

\footnotetext{
${ }^{21}$ Ignacio Hidalgo de CISNEROS, Cambio de rumbo, p. 82, Vitoria-Gasteiz, Ikusager Ediciones, 2001 (2a edición).

${ }^{22}$ Indalecio PRIETO, Discursos parlamentarios sobre la Guerra de Marruecos, p. 26, Málaga, Editorial Algazara, 2003.
} 
entre los oficiales y otras personas, cuya complicidad era preciso garantizar. Los beneficios se repartían entre los jefes y oficiales implicados, en cantidades que iban desde el intendente jefe, que recibía 60.000 pesetas, los demás jefes, 40.000, o capitanes, 30.000, y así sucesivamente. Todos los implicados en la trama llevaban un gran tren de vida, eran asiduos de las casas de juego y los prostíbulos, y se dedicaban a adquirir propiedades en la Península.

La trama corrupta se destapó cuando el capitán Manuel Jordán quiso quedarse con el millón y pico de pesetas procedentes de las "economías" de un mes, con cuyo fin comunicó a sus compañeros, que si no aceptaban que se quedara con la cantidad mencionada, después de lo cual pediría la separación del servicio, denunciaría a las autoridades el sistema utilizado para obtener beneficios de las "economías" practicadas. El escándalo no tardó en trascender, toda vez que ya había sospechas de irregularidades en el parque militar de Larache, el capitán Jordán fue detenido el 2 de septiembre, y el dinero descubierto, tras efectuar un registro en un garaje de la empresa Garzalla, que hacía el servicio Larache-Tánger-Alcazarquivir, uno de cuyos principales accionistas era el capitán Jordán. Oculto allí entre unos bidones de gasolina y diversas herramientas apareció envuelto en varios paquetes el millón y medio de pesetas. Los oficiales del parque de Larache fueron encarcelados, pero la investigación del juez instructor no se limitó a esa ciudad, sino que también era habitual en otros parques militares, sobre los que también pesaban sospechas de graves irregularidades. Los medios utilizados para desfalcar dinero eran varios: cobrar comisiones sobre las compras y hacer que el Estado pagara productos a un precio superior al de la compra, obligando con frecuencia a los proveedores a firmar recibos en blanco; dar a los cuerpos de tropa pesos falsos, aprovechando un descuido o amañando la báscula; hacer trapicheos con los cuerpos de tropa, pagándoles en metálico, a precios reducidos, mercancías no suministradas, que hacían como si efectivamente lo hubiesen sido $^{23}$.

A las gratificaciones por residencia- que incitaban a muchos militares a pedir que los destinaran a Marruecos, donde los sueldos eran más elevados-, se sumaban otras ventajas que, independientemente de los posibles desfalcos, consistían en

\footnotetext{
${ }^{23}$ Rafael LÓPEZ RIENDA, El escándalo del millón de Larache. Datos, antecedentes y derivaciones de las inmoralidades en Marruecos, Madrid, Sáez Hermanos, 1922.
} 
dedicarse a los negocios o en ejercer al mismo tiempo otras profesiones rentables, desatendiendo sus deberes en el ejército ${ }^{24}$. Una práctica habitual entre los militares era la adquisición de propiedades. Muchas de las fincas urbanas de Ceuta y Melilla pertenecían a miembros del ejército, aunque en el registro figuraban inscritas a nombre de sus esposas, suegras o hermanas. Era evidente que, por mucho que tratasen de ahorrar de sus pagas, éstas no daban para muchas alegrías, y, desde luego, en ningún caso, para la compra de fincas, algunas de ellas de alto precio ${ }^{25}$. Para evitar estos negocios, ajenos a su profesión, se dictó el 12 de febrero de 1917 una Real Orden, en virtud de la cual se prohibía a los militares dedicarse a ellas, aunque de nada o poco sirvió, al parecer, toda vez que al Juzgado seguían llegando denuncias anónimas que probaban la persistencia de esa práctica ${ }^{26}$.

Otro de los sectores donde se podían obtener fácilmente beneficios ilícitos eran las obras públicas, particularmente la construcción de carreteras, como nos relata en La Ruta, segunda parte de su famosa trilogía La forja de un rebelde, Arturo Barea, que lo vivió en primera persona cuando cumplía su servicio militar en Marruecos ${ }^{27}$. Para poner en pie este negocio, tenían que estar de acuerdo todas las partes interesadas, como supo pronto Barea, a quien no tardaron en poner al corriente del asunto. El contratista de la piedra tenía a sus órdenes a un equipo de "moros", unos poniendo barrenos en la cantera, y otros, machacando la piedra. La compañía daba al contratista la dinamita que él pagaba, y la compañía le pagaba, luego, cada metro cúbico de piedra. La función de Barea consistía en anotar la dinamita que gastaba el contratista y los metros cúbicos de piedra que les daba. A fines de mes, liquidaban cuentas. A veces, los "moros" que trabajaban para el contratista ayudaban al ejército a desmontar el terreno, y, en este caso, sucedía lo mismo: a tantos metros cúbicos de tierra, tantas pesetas. En este negocio, el contratista se llevaba una tercera parte de los negocios, la otra tercera parte, Barea, y, por último, la otra tercera parte, el capitán. Éste, sin cuya complicidad no sería posible el negocio, estaba, por supuesto, en la combinación, y,

\footnotetext{
${ }^{24}$ Expediente Picasso, p. 72, Madrid, 1931.

${ }^{25}$ Indalecio PRIETO, Discursos parlamentarios sobre la guerra de Marruecos, discurso del 21 de noviembre de 1922, p. 101, Málaga, Editorial Algazara, 2003.

${ }^{26}$ Expediente Picasso, p. 72.

${ }^{27}$ Arturo BAREA, La forja de un rebelde, II, La Ruta, Buenos Aires, Editorial Losada, 1966. Todos los entrecomillados y el relato de Barea se encuentran en las páginas 255-259 del citado libro.
} 
ahora, solo faltaba que Barea lo aprobara, con cuyo fin, el capitán le explicó los intríngulis. El Estado español ejecutaba todas sus obras siguiendo dos procedimientos: por contrata o por gestión directa. En el primer caso, se sacaba la obra a subasta y se pagaba al contratista la cantidad convenida; en el segundo caso, después de calculado el importe, la administración se ocupaba directamente de las obras y pagaba los jornales y los materiales. La carretera aquella, de la que habla Barea, se estaba construyendo por el procedimiento de la gestión directa, lo que significaba que era el ejército el que se encargaba de comprar los materiales y de pagar los jornales.

La Comandancia de Obras de Tetuán se ocupaba de la parte técnica y administrativa. Los soldados que trabajaban en la obra cobraban 2,50 pesetas, Barea, que era sargento, seis, y los oficiales, doce. Según el capitán, todos obtenían un gran beneficio. A los soldados se les pagaba solo 1,50 en dinero, y el resto iba en mejoras en la comida, con lo cual, decía el capitán, no hacía falta "robarles nada en el rancho y en la ropa". Este cínico comentario es revelador de la práctica generalizada de hacer "economías" y sacar los correspondientes "beneficios" robando a los soldados en el rancho. El capitán siguió explicando a Barea cómo funcionaba aquel tinglado. La compañía tenía un fondo particular, que se alimentaba de las economías realizadas sobre la cantidad presupuestada. Aunque tenían ciento once hombres, no todos trabajaban, unos, por estar enfermos, otros, con permiso, o por otras razones, lo que no impedía que el presupuesto siguiera siendo para el citado número y que los jornales fueran ciento once. Naturalmente, el que no trabajaba no cobraba, y, entonces el sobrante de los jornales iba a la compañía. Con los jornaleros marroquíes sucedía lo mismo. El presupuesto era para cuatrocientos, pero la cuadrilla nunca estaba completa, y, en realidad, solían ser unos trescientos cincuenta. Como el presupuesto era para cuatrocientos, se añadían cincuenta nombres árabes ficticios para que cuadraran los números. Con el contratista de obras pasaba lo mismo. Él sacaba la piedra y el ejército se la pagaba. Ya se sabía que cada kilómetro de carretera necesitaba tantos metros de piedra, pero si tuviera cinco centímetros menos de piedra, ello representaría unos doscientos metros cúbicos en kilómetro. Se trataba sencillamente de poner "algo más en la cuenta".

El capitán le había explicado bien a Barea el mecanismo de los jornaleros y del contratista, pero no le había ofrecido nada, como si quisiera todo para él. Tuvieron que 
aclararle luego los demás cómo ellos podían también beneficiarse. Se trataba de que los jornales no podían ser siempre los mismos, sino que las cifras cambiaban para no levantar sospechas. Entonces ellos se reservaban diez jornales de los "moros", que eran diez duros diarios para los cinco. En cuanto al teniente y el alférez, el primero era millonario y de aquello no sabía nada, y respecto del segundo, sus beneficios eran por partida doble, ya que tenía una parte con el capitán y otra con los demás. En el reparto entraban también los de la Comandancia de Tetuán, es decir que el capitán repartía sus beneficios con el comandante, sin cuya connivencia no podían hacer nada. Era un tinglado perfectamente concebido, en el que todos eran cómplices, como medio más eficaz de garantizar el silencio. Ninguno pensaba que aquello fuera robar, porque si robaban a alguien era al Estado, cuando, en realidad, era éste el que los robaba a ellos, pagándoles unos salarios de hambre con los que no se podía vivir. Con esta argumentación justificaban su participación en aquel fraude, que trataban de presentar como algo justo y perfectamente normal. Esto último sí lo era, pues estaba tan generalizado en el ejército de Marruecos, que se había convertido en una "costumbre". Redes corruptas como ésta eran moneda corriente y estaban tan arraigadas que era difícil poder terminar con ellas.

En los años de la Segunda República hubo intentos de moralizar la administración del Protectorado, reducir la abultada burocracia y terminar con la corrupción. En unas declaraciones, el alto comisario, Luciano López Ferrer, se refería, dentro de la política de reformas del Gobierno provisional, a la necesidad de poner coto al escándalo de las compras y ventas y de las adjudicaciones en los mercados del Estado $^{28}$. Era, en efecto, en las compras y ventas y en las adjudicaciones en los mercados del Estado, de donde los implicados en la trama sacaban sobre todo sabrosas tajadas. El debate del 29 de marzo de 1932 en las Cortes sobre el presupuesto de Marruecos, varios diputados criticaron duramente la gestión del alto comisario López Ferrer, particularmente el radical-socialista Joaquín Pérez Madrigal, quien criticó los gastos exagerados de una burocracia inútil y la creación de puestos para amigos de las autoridades de la Zona. La República no podía seguir pagando, argüía el parlamentario, a esos innumerables funcionarios que vivían allí como en una

\footnotetext{
${ }^{28}$ Declaraciones al redactor jefe de La Dépêche Algérienne, J. Cazenave, el 24 de junio de 1931.
} 
finca de recreo ${ }^{29}$. En las sesiones del 3 y del 22 de diciembre volvían los ataques contra López Ferrer. Pérez Madrigal lo acusaba, en su intervención del 3 de diciembre, de proseguir en Marruecos la misma política que en tiempos de la Monarquía, y de rodearse de funcionarios que le eran adictos. Para el diputado radical-socialista, la política de López Ferrer era un cúmulo de errores. Se refirió a los sueldos y gratificaciones de que disfrutaban, según él, los funcionarios amigos del alto comisario. En la sesión del 22 de diciembre, Eduardo Ortega y Gasset, miembro, primero, del partido radical-socialista, y, desde junio de 1932, de la izquierda radical-socialista, acusó a López Ferrer de seguir una política de despilfarro y de favorecer a funcionarios y personajes ultrarreaccionarios. Mientras López Ferrer siguiera en Marruecos, sería imposible, según Eduardo Ortega y Gasset, rectificar los errores del pasado y sanear la administración del Protectorado ${ }^{30}$.

En defensa de la gestión del alto comisario salieron tanto el presidente del Consejo, Manuel Azaña, como el socialista Indalecio Prieto. El primero, ya en la sesión del 29 de marzo de 1932, había defendido la política de López Ferrer en el Protectorado. Para Azaña, una larga guerra había creado allí una industria y un comercio, que se vieron paralizados cuando se instauró la paz. En Marruecos había, además, según Azaña, una burocracia costosa, lo mismo que la que sufría España, pero más insoportable porque disfrutaba de sueldos más elevados. Azaña trataba de explicar las razones de la situación creada en Marruecos por años de guerra, en los que, al socaire del ejército expedicionario, florecieron y prosperaron toda una serie de actividades comerciales ${ }^{31}$. La realidad era que muchos de los que habían prosperado con el comercio buscaban ahora reconvertirse y dedicarse a otros negocios lucrativos.

\footnotetext{
29 Joaquín PÉREZ MADRIGAL, Diario de Sesiones de la Cortes Constituyentes de la República Española, sesión celebrada el día 29 de marzo de 1932. Pérez Madrigal, que formaba parte de un grupo ferozmente izquierdista y antigubernamental, conocido como el de los "jabalíes", abandonó luego el partido radical-socialista, para pasarse al partido radical de Lerroux, y, en la guerra civil se hizo franquista y asiduo colaborador de Radio Nacional de España. En su deriva derechista, terminaría abrazando el catolicismo más integrista y ultramontano.

${ }^{30}$ Eduardo ORTEGA Y GASSET, Diario de Sesiones de las Cortes Constituyentes de la República Española, sesión celebrada el 22 de diciembre de 1932.

${ }^{31}$ Manuel AZAÑA, Diario de Sesiones de las Cortes Constituyentes de la República Española, sesión celebrada el 29 de marzo de 1932.
} 
A lo largo de los años se habían ido creando entre ellos y los altos cargos del Protectorado un entramado de intereses que los privilegiaban llegada la hora de solicitar adjudicaciones en los mercados del Estado. Para llevar a cabo sus planes de desarrollo en el Protectorado, todos los altos comisarios tuvieron entre sus máximas prioridades las obras públicas, sector en el que, ya fuera por gestión directa o por concurso público, los adjudicatarios sacaban, a base de trampas y artimañas, pingües beneficios. Era muy difícil extirpar estas prácticas corruptas tan fuertemente arraigadas. Por ello, pese a la voluntad de regeneración y moralización de los servicios de la Administración de la Zona, la República no consiguió terminar con la lacra de la corrupción.

\section{La corrupción en la era franquista}

En el Protectorado la era franquista no se inició en 1939, después de terminada la guerra civil, sino en julio de 1936, desde el primer momento en que triunfó el golpe de Estado, primero en la ciudad de Melilla y, poco después en toda la Zona. Desde su cargo de Delegado de Asuntos Indígenas, que ocupó antes de ser nombrado alto comisario en abril de 1937, Juan Beigbeder fue el artífice de la política instaurada en el Protectorado por las nuevas autoridades franquistas ${ }^{32}$. De Franco había recibido personalmente la misión de ganar a la causa de los militares golpistas al nacionalismo marroquí, representado en la zona Norte sobre todo por Abdeljalek Torres. Era evidente que había que hacer ciertas concesiones y mantener un hábil ten con ten. Tomás García Figueras, uno de los principales representantes del militarismo africanista, describe bien los métodos utilizados por Beigbeder para atraerse a los nacionalistas marroquíes:

"[...] el coronel Beigbeder, con hábil y audaz política, emprendió su captación, para lo cual empleo medios psicológicos, presentando en primer lugar la figura del

\footnotetext{
${ }^{32}$ Sobre Beigbeder, véase particularmente el largo capítulo (pp. 257-335) que le dedica María Rosa DE MADARIAGA, en su obra, ya citada, Marruecos, ese gran desconocido. Breve historia del Protectorado español, en el que se analiza, sobre la base de fuentes de archivo, su gestión en relación con el nacionalismo marroquí y el reclutamiento de soldados marroquíes para el ejército de Franco. Sobre el papel fundamental que desempeñó Beigbeder en el reclutamiento de tropas marroquíes para el ejército franquista, véase particularmente María Rosa DE MADARIAGA, Los moros que trajo Franco, Madrid, Alianza Editorial, 2015, (edición corregida y aumentada).
} 
general Franco como el enemigo del ateísmo y protector del islam. Hizo regalos, creó cargos, halagó vanidades, manejó diestramente la palanca comercial de los permisos de importación y exportación, compró conciencias, sobornándolas, y empleó de forma exhaustiva todos los recursos del hombre que conoce a fondo la idiosincrasia del marroquí, ${ }^{33}$ (sic).

La tradicional "compra de voluntades" aparece con Beigbeder en su más perfecta y alta expresión. Aquí, ya no se trataba de "moros adictos" de las cabilas, a los que se abonaban cantidades a cambio de sus servicios, sino de representantes de la gran burguesía tetuaní, cuya adhesión era preciso conseguir, a cambio de favores, sinecuras y prebendas.

Durante el mandato de Beigbeder como alto comisario (abril de 1937-agosto de 1939), las condiciones de vida en el Protectorado se hicieron cada vez más difíciles y el malestar iba en aumento. Ya no era solo la represión feroz que se abatió sobre todo lo que oliera a "rojo", ya fuera militar o civil, sino también por el alza vertiginosa de los precios de los productos. Aunque se habían instalado mecanismos para el control de las monedas, las importaciones y las exportaciones y el mercado interior, su eficacia en la Zona se encontraba gravemente lastrada por los sobornos y la urgente necesidad de las autoridades españolas de tener contentos a los marroquíes. Pese a los esfuerzos por mantener sin cambios el coste de la vida anterior al de la guerra, la situación quedó fuera de control en la Zona española, donde una aplicación rápida de los precios fijados oficialmente se traducía en un mercado desprovisto de suministros, y un aflojamiento del control permitía en un instante la renovación de los suministros existentes, pero a precios que podían ser más del doble. El aumento de los precios ocasionaba, como es lógico imaginar, incontables penurias para las clases medias y las familias con ingresos más bajos ${ }^{34}$.

A ahondar aún más el malestar en la población contribuían los múltiples casos de corrupción, notorios sobre todo en servicios públicos como las aduanas y los centros de mando. Los salvoconductos podían obtenerse por sumas que iban desde las 50 a las 200 pesetas. Los paquetes se franqueaban por libras, calculadas a 90 pesetas la libra, más una importante prima. Dado que muchos paquetes eran

\footnotetext{
${ }^{33}$ Tomás GARCÏA FIGUERAS, largo informe inédito sobre el nacionalismo marroquí de la Zona Norte, Archivo General de la Administración (AGA), Sección África, Fondo Marruecos, Caja 81/2382.

${ }^{34}$ Informe del cónsul de Gran Bretaña en Tánger, del 3 de diciembre de 1938, FO 371/22577.
} 
declarados como "muestras", la fuerte prima iba a parar a los bolsillos del funcionario de aduanas de turno. Además, era del dominio público que los permisos de importación solo podían obtenerlos los comerciantes que se las ingeniaban para "untar" discretamente a los funcionarios que los expedían ${ }^{35}$. En Larache, como en otros lugares de la Zona, el soborno de los funcionarios de aduanas desempeñaba un importante papel en los negocios locales y permitía muchas importaciones no autorizadas. Los funcionarios de aduanas estaban muy mal pagados y suplían la escasez de la paga con "negocios" paralelos. Los militares suplían también su exigua paga recurriendo a medios ajenos a sus funciones castrenses ${ }^{36}$.

La penuria, la escasez de alimentos y la corrupción hacían que, para la mayoría de la población, tanto española como marroquí, la llamada "Zona feliz" no lo fuera tanto. La gestión económica de Beigbeder, lejos de constituir una hábil y complicada ingeniería financiera, consistía en imponer fuertes multas a personas acusadas de haber traicionado la "causa nacional" y de participar en "actividades masónicas". Era un "atraco camuflado", basado en leyes franquistas. Las víctimas de estos "atracos legales" eran, en general, masones y judíos, cuyas sanciones pecuniarias alcanzaban a veces sumas elevadísimas, que proporcionaban importantes ingresos a la administración del Protectorado. En la prensa española de la Zona aparecían regularmente los nombres de los multados, junto con las sumas que estaban obligados a abonar. Todos los avisos de las sanciones llevaban la firma del alto comisario Juan Beigbeder $^{37}$.

Tras el nombramiento de Beigbeder ministro de Asuntos Exteriores el 9 de agosto de 1939, le sucedió en el puesto de alto comisario el general de brigada Carlos Asensio Cabanillas, quien había hecho parte de su carrera en Marruecos y mandaba en febrero de 1936 el grupo de Regulares nº 1 de Tetuán. Asensio Cabanillas formaba parte del sector africanista del Ejército que apoyó desde el primer momento el alzamiento militar de julio de 1936. Después de terminada la guerra civil, una vez que los vencedores no necesitaban ya del silencio cómplice de los nacionalistas

\footnotetext{
${ }^{35}$ Informe semanal del cónsul de Gran Bretaña en Tetuán, 21 de enero de 1938, FO 371/22575.

${ }^{36}$ Visita del cónsul de Gran Bretaña en Tetuán a Larache, Alcazarquivir y Uazán, 11 de abril de 1938 , Ibidem.

${ }^{37}$ María Rosa DE MADARIAGA, Marruecos, ese gran desconocido... pp. 276-278.
} 
marroquíes para la recluta de miles de soldados, había que reconsiderar muchas de las concesiones que les habían sido hechas por Beigbeder. Ante la necesidad de un mayor endurecimiento de la actitud hacia el nacionalismo marroquí, se consideró oportuno revocar a Asensio y sustituirlo el 13 de mayo de 1941 por el general Orgaz, con experiencia en el cargo de alto comisario, por haberlo ocupado ya unos meses en 1936, y considerado mucho más duro y rígido que Asensio. Durante ninguno de los dos mandatos se adoptaron medidas contra la corrupción que permeaba todos los niveles de la administración del Protectorado. Después de terminada la Segunda Guerra Mundial, la nueva situación creada exigía también una renovación de la política en el Protectorado, para llevar a cabo la cual ya no servía el general Orgaz, cuyas relaciones con los nacionalistas marroquíes, especialmente con Abdeljalek Torres, eran pésimas, sin olvidar que la derrota de las potencias del Eje y las pasadas simpatías pronazis de Orgaz no lo hacían tampoco la persona más recomendable ${ }^{38}$. De cara a la opinión internacional, se necesitaba alguien más presentable, alguien con ideas de preferencia monárquicas. La elección recayó en el general José Enrique Varela, que reemplazó a Orgaz el 3 de marzo de $1945^{39}$. Veterano de Marruecos, donde sirvió en las tropas Regulares, participó en la guerra del Rif y se distinguió en diversas acciones que le valieron la concesión por dos veces de la Cruz Laureada de San Fernando, la máxima condecoración del ejército español. La mayoría de sus ascensos lo fueron por méritos de guerra en Marruecos. Participó en el intento de golpe de Estado del general Sanjurjo en agosto de 1932, por lo que fue detenido y preso en Sevilla. En 1935, con el gobierno de la derecha y siendo ministro de la Guerra Gil Robles, fue ascendido a general. Ni que decir tiene que Varela tuvo una activa participación en la preparación de los planes del golpe militar de julio de 1936 contra el gobierno legítimo de la República. Al finalizar la guerra tenía el grado de general de división y Franco lo nombró ministro del Ejército, cargo que desempeñó de 1939 a

\footnotetext{
${ }^{38}$ Sobre las relaciones de Orgaz con los nacionalistas de la Zona Norte, de 1941 a 1945, véase Robert REZETTE, Les partis politiques marocains, p. 149, París, Armand Colin, 1955; Jean WOLF, Les secrets du Maroc espagnol. L'épopée d'Abdelkhalek Torrès 1910-1970, pp. 230-231, París-Casablanca, BallandEDDIF, 1994; Charles-André JULIEN, Le Maroc face aux impérialismes, 1415-1956, p. 189, París, Les Éditions du Jaguar, 2011 (1 ${ }^{\text {a }}$ edición, 1978); María Rosa DE MADARIAGA, Marruecos, ese gran desconocido..., pp. 351-352.

${ }^{39}$ Sobre la gestión del general Varela como alto comisario, véase particularmente María Rosa DE MADARIAGA, Marruecos, ese gran desconocido..., pp. 351. -369
} 
septiembre de 1942, en que cesó después de un incidente violento con un grupo de falangistas.

Varela era monárquico, sí, pero no alfonsino, sino carlista. Su matrimonio a finales de octubre de 1941 con Casilda Ampuera de Gandarias, de una adinerada familia bilbaína, también carlista, lo vinculaba aún más a ese movimiento. La noticia de su nombramiento de alto comisario fue muy bien acogida en los medios diplomáticos británicos, como lo demuestra el siguiente despacho de la embajada británica en Madrid:

"El general Varela es un oficial competente y experimentado, un monárquico acérrimo y amigo de los aliados. Dimitió de su puesto de ministro de la Guerra en septiembre de 1942, como consecuencia de un atentado contra su vida perpetrado por un grupo de extremistas de Falange que le arrojaron una bomba, en el momento en que salía de la iglesia de Begoña después de una ceremonia oficial. Debería resultar mucho mejor que el general Orgaz desde el punto de vista de los intereses británicos en la Zona española y en Tánger. Es de clase media y se ha casado recientemente con una señora rica de Bilbao, 40 .

No corresponde hablar aquí de la política aplicada por Varela en el Protectorado, salvo en lo referente al tema que nos ocupa, aunque su mandato sí se podría resumir de manera lacónica en que fueron seis años de dura represión y férrea dictadura. Como se sabe, Varela falleció el 24 de marzo de 1951 en Tánger de una enfermedad incurable. Con ocasión de su muerte, la prensa española, tanto de la Península, como local, se volcó con Varela, a quien dedicó una profusión de loas y alabanzas como "héroe nacional". De todo lo que hemos podido ver sobre Varela nos parece que el testimonio que refleja con más exactitud y rigor lo que fue el personaje y lo que fueron sus seis años de "proconsulado" al frente de la Alta Comisaría es un largo informe del cónsul británico en Tetuán ${ }^{41}$. Este testimonio tiene tanto más valor cuanto el nombramiento de Varela había sido bien acogido por los medios diplomáticos británicos y el propio cónsul en su informe reconocía que Varela había sido un "valiente soldado", pero, añadía, "no un administrador". También afirmaba que, aunque Varela fuera él mismo honrado, permitió que en su entorno prosperara una "corrupción

\footnotetext{
${ }^{40}$ Nota de la Embajada británica en Madrid al consulado británico en Tetuán, del 15 de marzo de 1945, FO 371/49346.

${ }^{41}$ Informe del cónsul británico en Tetuán, del 31 de marzo de 1951, FO 371/90268.
} 
generalizada". El cónsul también admitía que Varela había sido un "excelente marido y padre", pero cosa bien distinta de ese Varela era el Varela alto comisario, en el que su omnímodo poder dejaba que afloraran otros rasgos menos amables de su carácter. El informe del cónsul comprende tres apartados: el racionamiento en la Zona, la represión y la corrupción. El balance es demoledor. Aquí vamos a referirnos únicamente al primero y al tercer apartado. Al primero, por cuanto el tema del racionamiento guarda estrecha relación con el de la corrupción.

El racionamiento de artículos de primera necesidad estuvo en vigor desde el principio de la guerra civil en 1936, aunque las cartillas de racionamiento se establecieron oficialmente en España en mayo de 1939. Era obvio que los motivos dados para su establecimiento habían ya desaparecido, y, si la situación se perpetuaba, era sobre todo debido a una serie de intereses creados. Artículos como el azúcar, el arroz, el aceite, el pan, las judías, eran a veces objeto de una economía de trueque, y el intercambio de productos en el mercado negro dio origen al estraperlo. Las cartillas de racionamiento no se suprimieron oficialmente hasta el 22 de marzo de 1952, es decir que el sistema, lo mismo que en España, persistía en la zona española de Marruecos.

Un ejemplo de cómo funcionaba el sistema nos lo da la Oficina Territorial de la cabila de Anyera, aledaña a Tánger. En 1951, la Intervención territorial de Anyera había tenido 90.000 cartillas de racionamiento impresas en los talleres de impresión Mahdiya, de donde procedían las informaciones. Las cartillas de racionamiento contenían cupones para todos los artículos racionados. Si se tenía en cuenta que una familia rural marroquí estaba compuesta de un promedio de cuatro personas, la población de esta región tendría 360.000 habitantes (en realidad, eran 34.536 personas en total, de acuerdo con el censo de 1945, y, en 1951, ascenderían a 36.000). La Intervención comarcal hacía los arreglos necesarios para hacerse cargo de las raciones anuales de 360.000 personas, es decir, un cuarto de aceite de oliva por persona a la semana, o cuatro litros al mes para cada cartilla de racionamiento (según el promedio de familia indicado). Cuando llegaban los suministros, de aceite o de otros alimentos, quedaban "congelados", es decir, solo se expedía, por ejemplo, un litro de aceite al mes para cada cartilla, lo que significaba para cada familia. La fabulosa cantidad de productos alimentarios, aceite y otros que quedaban, eran distribuidos 
entre los diversos interventores territoriales elegidos por la Delegación de Asunto Indígenas, quienes se dedicaban luego a venderlos a precios exorbitantes. Los cabileños se veían obligados a vender las raciones necesarias para su sustento. Todas las oficinas españolas se beneficiaban de la situación, llegando a formar una compacta alianza, cuyos miembros solo aspiraban a lucrarse y hacerse ricos a expensas del empobrecimiento sistemático de los marroquíes. Los titulares de las cartillas se veían obligados a comprarlas a un precio muy superior. Su coste, que era solo en realidad de una peseta cada una, era recuperado por los beneficiarios multiplicado por cuarenta o cincuenta.

La libertad de comercio, anunciada por el alto comisario en uno de sus discursos, nunca llegó a aplicarse. Todos los productos que circulaban entre el campo y las ciudades, ya fueran pollos, corderos, cabras, vacas, leña carbón vegetal, aceite, té, etc. (excepto los huevos hasta cien unidades y las hortalizas hasta $160 \mathrm{~kg}$ ) seguían sujetos a la "guía" o permiso que expedía con este fin la Delegación de Hacienda, la cual, lo mismo que las demás delegaciones, estaba dictada por los antecedentes políticos de los titulares y la consideración en que los tenían las autoridades de la Administración española.

Sometida a estas condiciones, la economía solo beneficiaba a un sector muy reducido de la población marroquí, un puñado de personas, algunas de las cuales eran, además, naturalizados españoles. Los impuestos sobre las ventas o "derechos de puerta", que afectaban solo a las clases más pobres del país, es decir, a los cabileños que iban a vender sus productos y proveerse de uno o dos artículos de primera necesidad, se incrementaron considerablemente. Los empleados del consejo municipal encargados de recaudar esos impuestos estaban cuidosamente elegidos por su falta de escrúpulos y su arbitrariedad. El resultado era que los ignorantes cabileños eran víctimas de enormes abusos respecto de las tarifas establecidas.

El general Varela dejó la zona de Protectorado en peor estado que cuando fue nombrado alto comisario. Nadie antes que él había gobernado por medio de una camarilla tan corrupta e ineficaz. El cónsul británico sostenía que, aunque Varela personalmente no robara, había tolerado que la corrupción, ya endémica en el Protectorado, arraigara aún más y se convirtiera en una lacra sistémica. Sin embargo, 
las últimas investigaciones llevadas a cabo por Ángel Viñas en los Archivos Nacionales británicos prueban que Varela, junto con otros generales de Franco, se había dejado comprar por los británicos para que España no entrara en la Segunda Guerra Mundial al lado de Alemania. Viñas comenta, a este respecto, que Varela "no necesitaba dinero", pero que "a nadie le amarga un dulce". En resumidas cuentas, las sumas percibidas hacían del bilaureado general, después de Nicolás Franco, el hombre clave en el dispositivo inicial del banquero Juan March, que era el encargado de distribuir las generosas dádivas ${ }^{42}$.

Varela tenía una especial querencia por los edificios caros y los ornamentos, a la que, dado el régimen imperante entonces en España, pudo dar rienda suelta sin ningún control ni la más leve crítica. En el Palacio del Monte, en Tánger, solo para cuando iba por allí los fines de semana, se fueron cinco millones de pesetas de contribuyentes españoles, y más de dos millones de los contribuyentes marroquíes y españoles se gastaron, sin necesidad alguna, en remodelar y redecorar todos los espacios destinados a vivienda de la Alta Comisaría, con paredes revestidas de azulejos, maderas talladas y mármoles de los más caros. Fue un alarde de lujo y ostentación, un derroche de dinero público, en el mismo momento en que Tetuán estaba inundado de refugiados hambrientos por la catastrófica sequía que asolaba las montañas de la Zona y que yacían y morían abandonados en las calles aledañas de la residencia del alto comisario, quien ni siquiera se había molestado en organizar una sopa de beneficencia. Esta escandalosa situación duró algún tiempo. De un lado, un derroche de riquezas en vanidades, y, de otro, hombres, mujeres y niños, muriendo de hambre en las calles por falta de un mendrugo de pan ${ }^{43}$.

La política de Varela fue la de favorecer ostensiblemente y sin el menor pudor a los amigos. Las recompensas no solo adoptaron la forma de permisos libres de

\footnotetext{
${ }^{42}$ Ángel VIÑAS, Sobornos. De cómo Churchill y March compraron a los generales de Franco, pp. 109s, 119, 154, 248, 290, 297, 327, 361, 441, 463s y 488. Barcelona, Crítica, 2016.

${ }^{43}$ La hambruna que padeció el Rif en los años cuarenta y tantos del pasado siglo hizo época y quedó profundamente grabado en la memoria colectiva. Todavía hoy la recuerdan los que la padecieron de niños. Fueron cientos de personas, hombres, mujeres y niños, los que abandonaron sus aduares, alimentándose de raíces por el camino y muriendo muchos de inanición, en busca de un mendrugo de pan en Tánger o en Tetuán. De esta hambruna existe un testimonio literario de gran calidad. Se trata de la novela El pan desnudo (o El pan a secas) del escritor marroquí Mohamed Chukri, quien él mismo, siendo un niño, recorrió ese camino a pie desde su cabila de origen, Beni Sicar, aledaña de Melilla, para dirigirse a Tánger.
} 
importación para automóviles y otras muchas mercancías dentro de un sistema sometido a rígidos controles de todas las formas de comercio. Los permisos no tardaban en ser vendidos, a cambio de dinero contante y sonante, a corredores que aparecían para comerciar con documentos tan útiles. Se daba también la libertad de utilizar el poder administrativo sin control para aumentar los beneficios personales. Ello favoreció la ya considerable propensión de los caídes y otros funcionaros públicos a la codicia.

Con Varela, la contribución del Estado español al presupuesto únicamente civil de Marruecos, aparte de todo el gasto militar, que era incalculable, casi se triplicó. De cincuenta millones de pesetas en 1944 pasó a ciento cuarenta millones en 1950, y había poco que mostrar de lo que se había hecho con ese dinero. Excepto por algunos nuevos edificios gubernamentales, la Zona era en 1951 más pobre, estaba peor organizada que en 1945 y su población se hallaba en una situación netamente peor. Varela construyó solo para aquellos de quienes dependía el régimen. El cónsul británico en Tetuán resumía así la gestión de Varela: "Hizo demasiado poco por los más y en exceso por los menos" ("He did too little for the many and too much for the $\left.f w^{\prime \prime}\right)^{44}$. Esta breve frase del cónsul británico sintetiza perfectamente la gestión de Varela, a la que el diplomático británico dedicó el largo y circunstanciado informe, en el que nos basamos para efectuar un balance de su mandato ${ }^{45}$.

Megalómano, ambicioso, el "primer soldado de España" (después, claro, del "generalísimo") amaba el poder, la gloria, el boato. Su puesto de alto comisario le hacía sentirse omnipotente para poner y quitar a su antojo, favorecer a los amigos con todo tipo de prebendas, y perseguir con saña a los que consideraba sus enemigos. Todo ello dentro de la más absoluta arbitrariedad, propia del déspota.

\footnotetext{
${ }^{44}$ Informe del cónsul británico en Tetuán, antes citado, del 31 de marzo de 1951, FO 371/90268.

${ }^{45}$ Para el mandato de Varela, nos hemos centrado sobre todo en los aspectos relacionados con el racionamiento y la corrupción en la zona española. Para el tema de la política represiva de Varela, véase, además del citado informe del cónsul británico, Gabriel CARDONA, Franco y sus generales. La manicura del tigre, Madrid, Temas de Hoy, 2001. Obras como Varela, el general antifascista de Franco, de Federico Martínez Roda, Madrid, La Esfera de los Libros, 2012, que constituyen lo que Ángel Viñas califica de "hagiografías", omiten, por supuesto, referirse al bilaureado general como a alguien susceptible de ser "sobornado". Ni que decir tiene que la documentación de Varela depositada en el Archivo Municipal de Cádiz, no contiene, por lo que he podido saber, ningún documento que incrimine a Varela en lo más mínimo, en su etapa de alto comisario de 1945 a 1951, en cuestiones relacionadas con la corrupción, tema central de este artículo.
} 
El 30 de marzo de 1951 era nombrado alto comisario el general Rafael García Valiño. Nacido en 1898, era de los militares africanistas surgidos en la década de los años 90 del pasado siglo, de los más jóvenes. Después de salir de la Academia de Toledo, se incorporó a los 18 años como teniente al ejército de África, participó en diversas operaciones y alcanzó el grado de comandante. Cuando se produjo el golpe militar del 18 de julio, García Valiño se incorporó desde el primer momento al ejército franquista, en el que quedó a las órdenes del general Mola. Participó activamente en la guerra civil al mando del tercio de requetés de Montejurra, ascendiendo sucesivamente al grado de teniente coronel, y al de coronel. Combatió en diversas batallas en el frente de Aragón, particularmente en la del Ebro, a raíz de la cual fue ascendido a general por méritos de guerra. Hay que señalar que su ascenso fue vertiginoso, pues en dos años pasó de comandante a general. Nombrado por Franco comandante general de Melilla, cargo que ocupó de 1939 a 1942, fue nombrado luego jefe del Estado mayor, y, después de ascender en 1947 a teniente general, pasó a ocuparse de la Capitanía de la VII Región Militar.

Desde su llegada a Tetuán el 30 de abril de 1951, García Valiño quiso mostrar sus distancias respecto de la gestión de Varela ${ }^{46}$. En su visita al Jalifa, le adelantó ya en grandes líneas algunas de las primeras medidas que pensaba tomar, entre las que mencionó en primer lugar el programa de obras públicas, que debería ser reducido, lo que implicaba que el gasto exorbitante de dinero público en planes destinados más a impresionar que a beneficiar a la Zona iba a ser recortado, y que se iba a abrir una investigación sobre el estado insatisfactorio de las obras recientemente terminadas en el nuevo acceso a Tetuán y a la carretera de Ceuta. De otro lado, se creía saber que, desde su nombramiento, se había pasado el tiempo leyendo, bajo la dirección expresa de Franco, todos los informes relativos a las quejas contra la corrupción, que le habían sido enviados a él y al Director de Marruecos y Colonias, y que habían quedado archivados desde los últimos cinco años ${ }^{47}$. Teniendo en cuenta que eran las obras públicas uno de los sectores en los que más proliferaban los casos de corrupción en el Protectorado, era sobre todo en éstas en las que más insistía García Valiño en que se

\footnotetext{
46 Sobre la gestión de García Valiño, véase María Rosa DE MADARIAGA, Marruecos, ese gran desconocido..., pp. 383-429.

${ }^{47}$ Informe del cónsul británico en Tetuán, del 2 de mayo de 1951, Ibídem.
} 
revisarían y solo se proseguirían las que fueran de provecho ${ }^{48}$, lo que era una manera de indicar que había habido muchas inútiles y también un enorme despilfarro.

No obstante, a medida que pasaba el tiempo, aquello no tenía visos de cambiar. Como señal de que las cosas seguían igual, todos los jefes de las delegaciones del gobierno jalifiano conservaban sus puestos y con menos temor que al principio a perder sus lucrativos empleos. Ninguna de las mejoras que se esperaban del alto comisario se había materializado, como tampoco su supuesta capacidad administrativa. Era cierto que en las carreteras podían verse menos automóviles oficiales, en los que viajaban menos mujeres, señal de que no se utilizaba tanto como antes para fines ajenos al servicio, y en otros campos como el de los precios de los productos, en los que la corrupción en forma de estraperlo, también parecía que se había producido algún cambio, aunque no pasara de ser un cambio efímero.

A pesar de que el alto comisario pretendía que desde su llegada había hecho que bajaran los precios de los productos alimentarios hasta un $50 \%$, eso era totalmente falso. Así, después de una visita de García Valiño a tiendas y mercados, en la que había mostrado interés por los productos y los precios, el precio del aceite de oliva había bajado de manera espectacular de 40 a 27 pesetas en el mercado negro, aunque tanto éste como los precios de otros productos no tardarían en volver a ser lo que eran. Las raciones de los artículos básicos seguían siendo tan escasas como antes, y, en el mercado negro, en el que las existencias fueron confiscadas sin ningún beneficio para los posibles consumidores, el aceite no solo era más caro que antes, sino casi imposible de obtener. El que se conocía como "aceite de la Aviación”, porque era importado por las Fuerzas Aéreas españolas y era robado o vendido como excedente, era el más caro por ser el de mejor calidad. A menos que el general García Valiño estuviera dispuesto y fuera capaz de librarse de la banda de altos funcionarios, bajo cuyo mando la obtención de beneficios personales alcanzó tales niveles de lucro, en condiciones tan seguras para ellos y para los beneficiados, y eso desde hacía tanto tiempo que esos hábitos estaban profundamente arraigados, los precios seguirian

\footnotetext{
${ }^{48}$ Informe del cónsul británico en Tetuán, del 15 de mayo de 1951, Ibídem.
} 
estando más altos de lo que deberían estar, los ricos seguirían haciéndose cada vez más ricos y los pobres más pobres, y la Zona en general seguiría estancada ${ }^{49}$.

La corrupción estaba tan generalizada que afectaba a todas las capas de la sociedad. Un incidente del que fue protagonista el hermano menor del Jalifa, Muley Ahmed, revela las actividades de contrabando en la frontera del Protectorado español con Tánger (aduana internacional del Borch), a las que se dedicaban gran número de personas, incluidas las de más alto rango. Al registrar el coche del mencionado personaje, no le permitieron penetrar en la Zona, a pesar de sus protestas y de alegar que era "el hermano del Jalifa". No hubo nada que hacer frente a un funcionario cumplidor, por una vez, de su deber. Le fueron requisadas mercancías que llevaba por valor de 250.000 pesetas. Rogó a los funcionarios de aduanas, que no dieran cuentas a su hermano ${ }^{50}$, pero ¿acaso el Jalifa ignoraba estos trapicheos? Aquí, el que no participaba directamente en algún desfalco, estafa o latrocinio o era cómplice de estos desmanes, constituía la excepción.

Por si no tuviera ya bastante con las numerosas pruebas de corrupción que continuamente afloraban en los distintos órganos de la administración, García Valiño se vio asimismo envuelto en asuntos que contribuyeron a enturbiar aún más su ya desdorada reputación. Empezaron a circular noticias sobre la amistad de García Valiño con personajes de dudosa moralidad en negocios, como era el caso del anterior alcalde de Melilla y Jefe Provincial del Movimiento, Rafael Álvarez Claro, de quien se había hecho muy amigo cuando era comandante general de la plaza ${ }^{51}$. Álvarez Claro era un acaudalado hombre de negocios melillense, con intereses en muy variados sectores económicos. Principal accionista de la compañía de transportes urbanos de Melilla, la Cooperativa Ómnibus de Automóviles (COA), era asimismo armador y propietario de buques dedicados al transporte de mercancías. Uno de esos buques, el Castillo de Jarandilla, que transportaba desde Santa Cruz de Tenerife bidones de gasolina a Melilla, se incendió, y las mercancías almacenadas en el muelle quedaron destruidas. Pero la gasolina de los 1600 bidones había sido previamente descargada y

\footnotetext{
${ }^{49}$ Informe del cónsul británico en Tetuán, del 15 de mayo de 1951, Ibídem.

${ }^{50}$ Boletín de Información Marroquí (Delegación de Asuntos Indígenas), 9 de octubre de 1953, AGA, Sección África, Fondo Marruecos, Caja 81/2375.

${ }^{51}$ Informe del cónsul británico en Tetuán, del 12 de junio de 1951, FO 371/90268.
} 
vendida. Pronto se difundió el rumor de que el incendió había sido provocado para cobrar el seguro de esa gasolina, que podía rondar las 500.000 pesetas, cantidad en la que se había asegurado la carga. Lo que pasó por accidente habría sido en realidad un fraude para cobrar el seguro ${ }^{52}$.

Nada se movía en Melilla sin contar con el acuerdo de los "rafaeles" como les llamaban a García Valiño y a Álvarez Claro. Ellos dos en compañía de otro melillense, Jacob Salama y Cía., banquero judío, cuya familia estaba asentada en la ciudad desde larga fecha y gozaba de la nacionalidad española, habían estado metidos en negocios de artículos de algodón racionados. Jacob Salama era representante en Melilla de la multinacional Shell, y se erigió desde el principio en uno de los principales colaboradores económicos del franquismo, haciendo que los petroleros de la Shell con destino a España tocaran en puertos bajo el control de los facciosos ${ }^{53}$. Circulaban noticias sobre otros muchos asuntos de dinero, de los que el trío habría sacado pingües beneficios.

García Valiño fue el último alto comisario. Como es sabido, el 2 de marzo de 1956 Francia ponía fin a su Protectorado en Marruecos, y el 6 de abril del mismo año España hacía lo propio con el suyo. Hecho llamativo fue que García Valiño no participase en las negociaciones entre las delegaciones española y marroquí ni en la ceremonia de firma de la declaración conjunta de independencia de Marruecos por parte de España ${ }^{54}$.

\footnotetext{
52 "El incendio del Castillo Jarandilla. Accidente o el mayor fraude de la Melilla de los años cuarenta", Historias de la Melilla marinera, 18 de noviembre de 2011.

${ }^{53}$ María Elena FERNÁNDEZ DÍAZ, "Hebreos y musulmanes durante la guerra civil en Melilla. Violencia política y represión", p. 242, UNED-Espacio, Tiempo y Forma, Serie V. Historia contemporánea, t. 24, 2012. La comunidad judía de la Zona española del Protectorado y de Ceuta y Melilla, adoptó hacia el golpe militar franquista actitudes diversas. Mientras que muchos fueron perseguidos, sometidos a fuertes multas, encarcelados o encerrados en campos de concentración como el de Zeluán, cerca de Melilla, por "rojos" o "desafectos al Glorioso Movimiento Nacional", otros, como la Banca Hassan y los judíos de Tetuán, expresaron desde el primer momento su adhesión a Franco, y suministraron al principio de la guerra el dinero que faltaba para las primeras compras de armas y municiones, véase a este respecto, María Rosa de MADARIAGA, Marruecos, ese gran desconocido... y sobre el campo de concentración de Zeluán, en el que había encerrados muchos judíos, op. cit., pp. 271-272.

${ }^{54}$ Sobre la relación entre Francia y España en la etapa de García Valiño, véase $M^{a}$ Concepción YBARRA, España y la descolonización del Magreb. Rivalidad hispano-francesa en Marruecos (19511961), Madrid, UNED, 1998.
} 
Como "virrey" de la Zona española, a García Valiño le habría gustado poder seguir beneficiándose de aquella situación privilegiada y que el régimen de Protectorado se perpetuase. Incluso llegó a pensar que su declarado apoyo al nacionalismo marroquí de la Zona Sur contra Francia sería recompensado con una posible secesión de la Zona Norte, que optaría por seguir bajo la tutela de España cuando los franceses se hubiesen ido. Naturalmente, eran solo elucubraciones de un megalómano. Desde el momento en que Francia había decidido abandonar la partida, la permanencia de España en la Zona Norte no tenía sentido. A España no le quedaba otra opción que evacuar la zona Norte. No hay que olvidar que el tratado de Protectorado del 30 de marzo de 1912 había sido firmado únicamente por Francia con el Sultán, y que la zona de Protectorado español era, de hecho, un "subarriendo" de Francia, una zona de influencia española en Marruecos, que Francia le había cedido a España ${ }^{55}$. Poco a poco hubo que ir desmantelando los diferentes órganos de la administración colonial. Las tropas españolas, que ascendían en 1956 a 71.000 hombres permanecieron todavía en Marruecos hasta finales de agosto de 1961, en que terminaron de replegarse a Ceuta y Melilla y a la Península. También los miles de funcionarios de aquella abultada burocracia tuvieron que replegarse. Termino con las mismas palabras con las que concluyo la Introducción de mi libro Marruecos, ese gran desconocido. Breve historia del Protectorado español (pp. 20-21 "[...] el balance que hago del Protectorado español sobre la base de la documentación consultada, no puede ser más negativo [...] La mayoría de las fuentes consultadas coinciden en señalar la corrupción profundamente arraigada que invadía todos los ámbitos de la sociedad. Ello no quita para que hubiera allí personas honradas, tanto civiles como militares, que trataron de cumplir lo mejor que pudieron con su obligación en las esferas de actividad en las que trabajaron: maestros, médicos, ingenieros, empleados del sector público o privado. Pero el sistema era corrupto y lo siguió siendo hasta el final".

\footnotetext{
${ }^{55}$ Véase a este respecto, María Rosa DE MADARIAGA, Marruecos, ese gran desconocido..., capítulo 2, titulado "El tratado de 1912, un "subarriendo de Francia", pp. 71-113.
} 